\title{
Elimination of Mycoplasma contamination in Chlamydia stocks as a result of in vivo passage or plaque isolation
}

\author{
Ira M. Sigar ${ }^{*}$, Justin H. Schripsema', Kathleen A. Kelly ${ }^{2}$, Ashlesh K. Murthy ${ }^{3}$, Srikanth Manam ${ }^{3}$ \\ and Kyle H. Ramsey ${ }^{1}$
}

\begin{abstract}
Objective: This study aims to eliminate Mycoplasma spp. contamination from laboratory stocks of Chlamydia spp. by in vivo passage or by plaque assay.

Results: We have described two methods of eliminating Mycoplasma contamination from Chlamydia laboratory stocks. We conclude that Mycoplasma species commonly contaminating chlamydial stocks do not survive passage in mice. Chlamydia may also be derived Mycoplasma-free by plaque assay.
\end{abstract}

Keywords: Chlamydia, Mycoplasma, Cell culture, Contamination, Plaque assay

\section{Introduction}

Bacteria of the class Chlamydiae are obligate intracellular pathogens and are commonly grown in mammalian cell lines such as McCoy, L929, or HeLa 229 cells. Unfortunately, cell culture is easily and commonly contaminated with Mycoplasma spp. Likewise, contamination of Chlamydia stocks and cultures by Mycoplasma spp. is common in laboratories and thus complicates interpretation of experimental results. Mycoplasma contamination has also been shown to confound interpretation of chlamydial serodiagnostic tests [1-4].

Detecting and confirming Mycoplasma in chlamydial culture can be challenging. Cultivation in broth and subsequently on agar was the long-held gold standard but can take more than 2 weeks for results. Nucleic acid detection has offered a more rapid approach to screening for Mycoplasma contamination, but a commercial test targeting Mycoplasma 16S ribosomal RNA by polymerase chain reaction (PCR) was subsequently found to cross-react due to sequence homology among

\footnotetext{
*Correspondence: isigar@midwestern.edu

${ }^{1}$ Microbiology and Immunology Department, Chicago College of Osteopathic Medicine, Midwestern University, SH-323H, 555 31st Street, Downers Grove, IL, USA

Full list of author information is available at the end of the article
}

Mycoplasma and Chlamydia spp. [5, 6]. A commercially available rapid test for Mycoplasma ATP synthase works more reliably and is both relatively sensitive and specific (MycoAlert $^{\mathrm{TM}}$, Lonza, Walkersville, MD). We now routinely use this assay to screen cell cultures and chlamydial stocks for mycoplasma in our laboratory. If positive by this test, we confirm our results with PCR and primers targeting the GPO-3 (general prokaryotic oligonucleotides) and MGSO (mycoplasma genus-specific oligonucleotides) sequences [7].

A finding of Mycoplasma contamination is further complicated by inadequate remedies to selectively target Mycoplasma over Chlamydia in vitro. For example, antibiotics (e.g., fluoroquinolones such as ciprofloxacin) possess equally potent antimicrobial effects on all species of Chlamydiae in vitro (authors' unpublished observations). Similarly, the newer anti-Mycoplasma compound, Plasmocin $^{\text {TM }}$ (InvivoGen, San Diego, California, USA) which is commercially promoted as a means to prevent or eliminate Mycoplasma contamination from various cell culture systems [8], is equally cidal for Chlamydia spp. (authors' unpublished observations). Although a colleague recently reported to us that she was able to successfully eliminate Mycoplasma from C. trachomatis, serovar L2, and also C. muridarum by treatment with Mynox $^{\circledR}$ (Minerva Biolabs, Berlin, Germany), we have

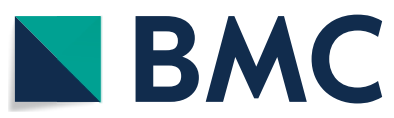

C The Author(s) 2018. This article is distributed under the terms of the Creative Commons Attribution 4.0 International License (http://creativecommons.org/licenses/by/4.0/), which permits unrestricted use, distribution, and reproduction in any medium, provided you give appropriate credit to the original author(s) and the source, provide a link to the Creative Commons license, and indicate if changes were made. The Creative Commons Public Domain Dedication waiver (http://creativecommons.org/ publicdomain/zero/1.0/) applies to the data made available in this article, unless otherwise stated. 
not yet verified these results (Jane C. Goodall, University of Cambridge, personal communication). With respect to this and other anti-mycoplasma treatments, we do not yet know of any that exhibit selective toxicity for Mycoplasma over Chlamydia. It is at least noteworthy that a recent report has found several Mycoplasma isolates resistant to each of these treatments [8]. Hence, a method for reliably and selectively targeting Mycoplasma spp. over Chlamydia spp., and thereby deriving a "pure" Chlamydia stock, is needed.

\section{Main text \\ Method \\ Chlamydia stocks}

Chlamydia muridarum mouse pneumonitis (MoPn) strain (Weiss), C. trachomatis serovar E/Bour and the $C$. pneumoniae (TW-183) were obtained and maintained by our laboratories. These stocks were positive for $\mathrm{Myco-}$ plasma contamination using the two detection methods as described below.

\section{Cell lines}

HeLa 229 cells were used for propagation of $C$. muridarum MoPn Weiss and C. trachomatis serovar E. Hep-2 cells were used for propagation of C. pneumoniae. The L929 cells were used for the plaque-forming assays. All cell lines are from American Type Culture Collection. Dulbecco's modification of Eagle's medium with $4.5 \mathrm{~g} / \mathrm{l}$ glucose, L-glutamine and sodium pyruvate (Cellgro-Mediatech, Manassas, VA) supplemented with $10 \%$ fetal calf-serum and gentamicin $(100 \mu \mathrm{g} / \mathrm{ml})$ was used. Before infection with Chlamydial sample, the cell

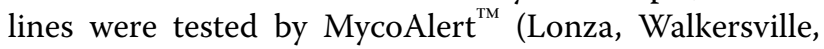
$\mathrm{MD})$ to ensure that they were negative for Mycoplasma.

\section{Animals}

Female BALB/c and $\mathrm{C} 3 \mathrm{H} / \mathrm{HeN}$ mice were used for $C$. muridarum infection; C57BL/6 female and male mice were used for C. trachomatis and C. pneumoniae consecutively. All mice were purchased from Charles River Laboratories International (Wilmington, MA). This study was approved by the Institutional Animal Care and Use Committee of Midwestern University.

\section{Decontamination procedures}

Two different decontamination procedures were used in this study. The first procedure was the in vivo method of passing chlamydial stock into mice. Mice [pretreated with Medroxy-progesterone acetate (Greenstone, Peapack, NJ) 7 days before infection] were infected intravaginally with $10^{5}$ IFU doses of Mycoplasma-positive of C. muridarum or C. trachomatis. On day 4 p.i. (post inoculation) or day 7 p.i. shedding of viable chlamydiae from the lower urogenital tract was assessed by the collection of cervical-vaginal swabs. All samples were frozen at $-80^{\circ} \mathrm{C}$. Samples were thawed and expanded in HeLa 229 cell culture monolayers as previously described in Cotter et al. [9].

For $C$. pneumoniae, mice were infected intranasally with $10^{5}$ IFU doses of Mycoplasma-positive of C. pneumoniae. On day 4 and 7 p.i. lungs were collected, homogenized and subsequent culturing of lung tissue material in Hep- 2 cell monolayers. The process of decontamination was first monitored using the MycoAlert ${ }^{\mathrm{TM}}$ detection kit. Then, the remaining sample can be passed to 6 or 12-well plates to extract DNA for Mycoplasma groupspecific PCR assay detection and to repeat the Mycoplasma detection by MycoAlert ${ }^{\mathrm{TM}}$.

The second procedure of decontamination Mycoplasma from Chlamydial stock was plaque-forming assay as previously described [10], with minor modification. Dilutions of chlamydial stock were inoculated by centrifugation at $1100 \times g$ for $1 \mathrm{~h}$ at $37^{\circ} \mathrm{C}$ onto confluent monolayer of L929 cells grown in 6-well tissue culture dishes. The infective inocula was then removed and the monolayers were overlaid with $1 \times$ DMEM, $10 \%$ FBS, $0.2 \%$ agarose, $0.2 \mu \mathrm{g} / \mathrm{mL}$ cyclohexamide, $50 \mu \mathrm{g} / \mathrm{ml}$ gentamicin, $100 \mu \mathrm{g} / \mathrm{mL}$ vancomycin, $0.5 \mu \mathrm{g} / \mathrm{ml}$ fungizone and incubated at $37{ }^{\circ} \mathrm{C}, 5 \% \mathrm{CO}_{2}$ for $5-7$ days. Plaque purifications were carried out by picking individual plaques into $100 \mu \mathrm{L}$ SPG buffer then aliquots into two $50 \mu \mathrm{l}$ suspensions and stored at $-80{ }^{\circ} \mathrm{C}$. The suspension was used to infect individual wells of a 24-well tissue culture dish containing Mycoplasma-free confluent monolayers of cell line. The same procedure of monitoring decontamination was performed as described above (Mycoalert and PCR). Note to confirm that the plaques contain Chlamydial DNA, a PCR amplification of 16S Ribosomal Chlamydia gene was done as described in Wooters et al. [11], using the same template for the Mycoplasma group-specific PCR assay.

\section{Detection of Mycoplasma contamination}

Two methods of detecting Mycoplasma contamination were done to all stocks and samples. These are MycoAlert $^{\mathrm{TM}}$ Mycoplasma Detection Kit and Mycoplasma group-specific PCR assay [5]. To use MycoAlert ${ }^{\mathrm{TM}}$ Mycoplasma Detection Kit, Chlamydial samples were infected into $24 \mathrm{~h}$ Mycoplasma-negative cell line monolayers in 24-well plates, using $\mathrm{MOI} \leq 3$. The plate was centrifuged for $1 \mathrm{~h}$ at $1100 \times g$ at $37^{\circ} \mathrm{C}$ then transferred to $37{ }^{\circ} \mathrm{C}, 5 \% \mathrm{CO}_{2}$ incubator. After $2 \mathrm{~h}$, the media was changed to cyclohexamide media $(0.5 \mu \mathrm{g} / \mathrm{ml})$. Following a $24 \mathrm{~h}$ incubation, $500 \mu \mathrm{l}$ samples were processed according to MycoAlert ${ }^{\mathrm{TM}}$ protocol. A sample is positive for Mycoplasma contamination when the ratio of 
B (second reading)/A (first reading) is greater than 1 . Reading was accomplished using TD-20/20 luminometer Turner designs (Sunnyvale, CA) with delay time $3 \mathrm{~s}$, and integration time $4 \mathrm{~s}$. Mycoplasma group-specific PCR assay was accomplished using template from Chlamydial DNA extraction, either from high-speed purification of Chlamydia's elementary bodies harvested from cell line or by scraping infected cell line directly. Extraction of DNA was accomplished using DNeasy Blood and Tissue kit (Qiagen, Valencia, CA) with 60-80 $\mu$ l elution. Five microliters of sample was added to $20 \mu \mathrm{l}$ of the following PCR mixture: 1X Taq PCR Master Mix (Qiagen) and $0.8 \mu \mathrm{M}$ each primers. A PCR protocol was used in Techne TC-412 (Techne, Burlington, NJ) with $94^{\circ} \mathrm{C}, 30 \mathrm{~s}$; $55{ }^{\circ} \mathrm{C}, 30 \mathrm{~s} ; 72{ }^{\circ} \mathrm{C}, 60 \mathrm{~s}$ for 35 amplification cycles using the primer pair of upstream primer GPO-3, 5'-GGGAGC AAACAGGATTAGATACCCT-3'; downstream primer
MGSO, 5'-TGCACCATCTGTCACTCTGTTAACCTC$3^{\prime}$. The $270 \mathrm{bp}$ of PCR product was analyzed by agarose electrophoresis.

\section{Results}

Recently, we re-derived selected C. muridarum stocks following in vivo passage in mice. Several of these were known to be contaminated with Mycoplasma spp. (Table 1). Following inoculation in mice and subsequent in vitro expansion, the C. muridarum stocks were found to be negative by MycoAlert ${ }^{\mathrm{TM}}$ and PCR (initial data not shown). A more detailed analysis of additional cell culture isolates derived following in vivo passage was then conducted-where we tested 3 sets of isolates. Each isolate was derived from cervical-vaginal swabs following intravaginal inoculation of mice (C. muridarum or C. trachomatis) $[12,13]$. In addition, lung homogenates of mice

Table 1 Effect of in vivo passage of Chlamydia spp. stocks on Mycoplasma contamination

\begin{tabular}{|c|c|c|c|c|c|}
\hline \multirow[t]{2}{*}{ Species (strain) route } & \multirow[t]{2}{*}{ Isolates tested (mouse strain) } & \multicolumn{2}{|c|}{ Result, in vitro pass 1} & \multicolumn{2}{|c|}{ Result, in vitro pass 2} \\
\hline & & MycoAlert $^{\mathrm{TM}}$ & $\mathrm{PCR}^{\mathrm{a}}$ & MycoAlert $^{\mathrm{TM}}$ & $\mathrm{PCR}^{\mathrm{a}}$ \\
\hline \multirow[t]{7}{*}{ C. muridarum (Weiss strain) intravaginal } & Culture stock ${ }^{b}$ & + & + & $+^{2}$ & + \\
\hline & $c-v^{c}$ swab $1(B A L B / c)$ day 4 & - & - & - & nd \\
\hline & c-v swab 2 (BALB/c) day 4 & - & - & - & nd \\
\hline & c-v swab 3 (BALB/c) day 4 & - & - & - & nd \\
\hline & $c-v$ swab $4(\mathrm{C} 3 \mathrm{H} / \mathrm{HeN})$ day 4 & - & - & - & nd \\
\hline & c-v swab $5(\mathrm{C} 3 \mathrm{H} / \mathrm{HeN})$ day 4 & - & - & - & nd \\
\hline & c-v swab $6(\mathrm{C} 3 \mathrm{H} / \mathrm{HeN})$ day 4 & - & - & - & nd \\
\hline \multirow[t]{9}{*}{ C. trachomatis (serovar E/Bour) intravaginal } & Culture stock ${ }^{\mathrm{b}}$ & + & + & + & + \\
\hline & c-v swab $1($ C57BL/6) day 4 & - & - & - & - \\
\hline & c-v swab 2 (C57BL/6) day 4 & - & - & - & - \\
\hline & c-v swab $3(\mathrm{C} 57 \mathrm{BL} / 6)$ day 4 & - & - & - & - \\
\hline & c-v swab 4 (C57BL/6) day 4 & - & - & - & - \\
\hline & c-v swab $5(\mathrm{C} 57 \mathrm{BL} / 6)$ day 7 & - & - & - & - \\
\hline & c-v swab 6 (C57BL/6) day 7 & - & - & - & - \\
\hline & c-v swab 7 (C57BL/6) day 7 & - & - & - & - \\
\hline & c-v swab 8 (C57BL/6) day 7 & - & - & - & - \\
\hline \multirow[t]{9}{*}{ C. pneumoniae (TW-183) intranasal } & Culture stock $\mathrm{k}^{\mathrm{b}}$ & + & + & + & + \\
\hline & Lung 1 (C57BL/6) day 4 & - & - & - & - \\
\hline & Lung 2 (C57BL/6) day 4 & - & - & - & - \\
\hline & Lung 3 (C57BL/6) day 4 & - & - & - & - \\
\hline & Lung 4 (C57BL/6) day 4 & - & - & - & - \\
\hline & Lung 5 (C57BL/6) day 7 & - & - & - & - \\
\hline & Lung 6 (C57BL/6) day 7 & - & - & - & - \\
\hline & Lung 7 (C57BL/6) day 7 & - & - & - & - \\
\hline & Lung 8 (C57BL/6) day 7 & - & - & - & - \\
\hline
\end{tabular}

a PCR for GPO-3/MGSO positive with a PCR product band at the anticipated size of $\sim 270$ bp on agarose gel electrophoresis. A positive control for chlamydial $16 \mathrm{rRNA}$ was included in each reaction

b All culture stocks of each of these strains repeatedly tested positive by MycoAlert ${ }^{\mathrm{TM}}$. In this assay, a before/after ratio of ATP of 1.0 or greater is considered a positive result by the manufacturer. All of our culture stocks were positive between 5.0 and 16.0 in multiple tests for each stock

c $\mathrm{c}-\mathrm{v}=$ cervical vaginal swab collected as previously described in Cotter et al. [9];

nd not determined 
inoculated intra-nasally with C. pneumoniae [14] were assessed. Each sample listed in Table 1 was derived following an initial isolation event from mouse samples and two subsequent passages in cell culture.

At each in vitro stage following in vivo sample collection, the sample was negative by MycoAlert ${ }^{\mathrm{TM}}$ and/ or by PCR (Table 1). In addition, several of these samples have since been tested again on other occasions and found to be negative by MycoAlert ${ }^{\mathrm{TM}}$ and PCR (data not shown). The data infer that the strain(s) of mycoplasma contaminating multiple stocks of chlamydiae, originally derived from various sources, are not compatible with growth in the mouse host. Hence, we have demonstrated that passage through a mouse host was able to cure the chlamydial isolates of the mycoplasma contamination.

Realizing that not all laboratories are able to conduct in vivo passage to re-derive a Mycoplasma-free isolate, we report a second, albeit less efficient, means to rid Chlamydia of Mycoplasma contamination. Many species and strains of Chlamydia are known to form plaques in mouse fibroblast monolayers such as the L929 cell line [13]. Recently, when preparing clonal chlamydial isolates of $C$. muridarum for genomic sequencing, we observed that, though initially Mycoplasma-contaminated, several plaque isolates were Mycoplasma-free when expanded further in vitro. We attempted this again and found the result, while not $100 \%$ efficacious, is repeatable (Table 2). Of the 22 plaque isolates tested: (1) 11 (50\%) were consistently negative for Mycoplasma contamination by MycoAlert ${ }^{\mathrm{TM}}$ assay and PCR following initial isolation and 2 in vitro expansion passages (plaque isolate numbers 10, 12-15 and 17-22); (2) nine were negative on MycoAlert after the first passage but were consistently PCR positive and became both MycoAlert and PCR + following the second passage (plaque isolate numbers 1-3, 5-8 and 11); (3) one isolate was only PCR + following the first in vitro passage and became negative by both assays thereafter (plaque isolate number 9); (4) one isolate was consistently positive on both assays (plaque isolate number 16) and (5) one isolate was consistently negative on MycoAlert but PCR positive on all passages (plaque isolate number 4). These results have been confirmed with further MycoAlert testing in several stocks of these isolates in subsequent passages (data not shown.)

\section{Discussion}

While we cannot speculate as to the origin of the $\mathrm{Myco}$ plasma contamination of our culture stocks-whether introduced by routine cell culture passage or from the original isolation-it is safe to assert that the Mycoplasma strains commonly contaminating Chlamydia in cell culture in our lab do not survive introduction into the mouse host. This is confirmed in both the
Table 2 Effect of plaque isolation assay on Mycoplasma contamination

\begin{tabular}{|c|c|c|c|c|}
\hline \multirow{2}{*}{$\begin{array}{l}\text { Plaque isolate } \\
\text { number }^{\mathrm{a}}\end{array}$} & \multicolumn{2}{|c|}{ Result, passage 1} & \multicolumn{2}{|c|}{ Result, passage 2} \\
\hline & MycoAlert $^{\mathrm{TM}}$ & PCR & MycoAlert $^{\mathrm{TM}}$ & PCR \\
\hline 1 & $-{ }^{\mathrm{b}}$ & + & + & + \\
\hline 2 & - & + & + & + \\
\hline 3 & - & + & + & + \\
\hline 4 & - & + & - & + \\
\hline 5 & - & + & + & + \\
\hline 6 & - & + & + & + \\
\hline 7 & - & + & + & + \\
\hline 8 & - & + & + & + \\
\hline 9 & - & + & - & - \\
\hline 10 & - & - & - & - \\
\hline 11 & - & + & + & + \\
\hline 12 & - & - & - & - \\
\hline 13 & - & - & - & - \\
\hline 14 & - & - & - & - \\
\hline 15 & - & - & - & - \\
\hline 16 & + & + & + & + \\
\hline 17 & - & - & - & - \\
\hline 18 & - & - & - & - \\
\hline 19 & - & - & - & - \\
\hline 20 & - & - & - & - \\
\hline 21 & - & - & - & - \\
\hline 22 & - & - & - & - \\
\hline
\end{tabular}

a Stock from which random plaques were selected was $C$. muridarum (Weiss strain) and were consistently positive by MycoAlert ${ }^{\mathrm{TM}}$

${ }^{b}$ All culture stocks of each of these strains repeatedly tested positive by MycoAlert ${ }^{\mathrm{TM}}$. In this assay, a before/after ratio of ATP of 1.0 or greater is considered a positive result by the manufacturer. All of our culture stocks were positive between 5.0 and 16.0 in multiple tests for each stock

chlamydial research laboratories at Midwestern University and the University of California at Los Angeles. Furthermore, the effect was independent of mouse strain and route of inoculation. It is important to note that we cannot state whether in vivo passage will select for isolates that will exhibit disparate chlamydial phenotype(s) in vitro or in vivo when compared to the parental strain [13].

The other alternative to eliminating Mycoplasma contamination is to conduct plaque isolation. Although we cannot speculate what the mechanism behind these observations are, we can assert that while somewhat tedious, plaque assay may be a viable alternative to removing Mycoplasma contamination in laboratories that lack the ability to conduct the above-described in vivo passages. It is highly recommended to use two methods of Mycoplasma detection from the plaque, such as MycoAlert and PCR, due to the inconsistent result of this decontamination process. It should be noted, that not all 
Chlamydia spp. form plaques in mammalian cell culture (e.g., C. pneumoniae). Hence, this technique may not be viable for all species and strains.

In summary, we have described two methods of eliminating Mycoplasma contamination from Chlamydia laboratory stocks. Depending on the capabilities of the laboratory and the chlamydial strains being used, one or both methods should be effective. We believe the information provided will be of use to the chlamydial research community.

\section{Limitations}

The size of study was limited due to Mycoplasma contamination of our Chlamydia stock (Additional file 1).

\section{Additional file}

Additional file 1. The ARRIVE Guidelines Checklist.

\begin{abstract}
Authors' contributions
IMS: conception of project, design of experiments, acquisition and analysis of data, review and assist with manuscript preparation. JHS: technical execution, input on design of experiments, acquisition and analysis of data, review of manuscript. KAK: conception of project with original idea, initial proof of concept, review of manuscript. AKM: conception of in vivo passage ( $C$. pneumoniae) and supervision of execution of that arm of the project, review of manuscript. SM: technical execution of in vivo passage (C. pneumoniae), acquisition of data, review of manuscript. KHR: conception of project in conversation with KAK and IMS: supervision of project from conception to finish, composition of original manuscript and review and approval of final edited version. All authors read and approved the final manuscript.
\end{abstract}

\section{Author details}

${ }^{1}$ Microbiology and Immunology Department, Chicago College of Osteopathic Medicine, Midwestern University, SH-323H, 555 31st Street, Downers Grove, IL, USA. ${ }^{2}$ Pathology and Laboratory Medicine, David Geffen School of Medicine, at UCLA, Los Angeles, CA, USA. ${ }^{3}$ College of Veterinary Medicine, Midwestern University, Glendale, AZ, USA.

\section{Acknowledgements}

The authors would like to acknowledge Deana Jasper and Tyler Mitchell for their assistance in conducting the presented experiments.

\section{Competing interests}

The authors declare that they have no competing interests.

\section{Availability of data and materials}

All data generated or analysed during this study are included in this published article [and its supplementary information files].

\section{Consent for publication}

Not applicable.

\section{Ethics approval and consent to participate}

All procedures related to Mycoplasma contamination and involving the use of animals in these studies were secondarily derived from specimens (tissues and swab) that were collected under separate protocols approved by the Midwestern University Institutional Animal Care and Use Committee (IACUC)
The Midwestern University animal facility is certified by, and the IACUC abides by, the Guide for the Care and Use of Laboratory Animals, published by the American Association for Accreditation of Laboratory Animal Care.

\section{Funding}

This project was funded by an intramural support from office of research and sponsored program of Midwestern University.

\section{Publisher's Note}

Springer Nature remains neutral with regard to jurisdictional claims in published maps and institutional affiliations.

Received: 2 March 2018 Accepted: 31 May 2018

Published online: 07 June 2018

\section{References}

1. Messmer TO, Black CM, Thacker WL. Mycoplasma contamination of chlamydiae isolated from clinical specimens. APMIS. 1994;102:793-6.

2. Huniche BS, Jensen LT, Birkelund S, Christiansen G. Mycoplasma contamination of Chlamydia pneumoniae isolates. Scand J Infect Dis. 1998;30:181-7.

3. Verkooyen RP, Sijmons M, Fries E, Van BA, Verbrugh HA. Widely used, commercially available Chlamydia pneumoniae antigen contaminated with mycoplasma. J Med Microbiol. 1997;46:419-24.

4. Krausse-Opatz B, Dollmann P, Zeidler H, Kuipers JG, Kohler L. Frequent contamination of Chlamydia trachomatis and Chlamydia pneumoniae strains with mycoplasma. Biological relevance and selective eradication of mycoplasma from chlamydial cultures with mupirocin. Med Microbiol Immunol. 2000;189:19-26.

5. Ossewaarde JM, Bestebroer T, Angulo AF. Application of a Mycoplasma group-specific PCR for monitoring decontamination of Mycoplasmainfected Chlamydia sp. strains. Appl Environ Microbiol. 1996;62:328-31.

6. Maass V, Kern JM, Poeckl M, Maass M. Sequence homologies between Mycoplasma and Chlamydia spp. lead to false-positive results in chlamydial cell cultures tested for mycoplasma contamination with a commercial PCR assay. J Clin Microbiol. 2011;49:3681-2.

7. van Kuppeveld FJ, van der Logt JT, Angulo AF, van Zoest MJ, Quint WG, Niesters HG, Galama JM, Melchers WJ. Genus- and species-specific identification of mycoplasmas by $16 \mathrm{~S}$ rRNA amplification. Appl Environ Microbiol. 1992;58:2606-15.

8. Uphoff CC, Denkmann SA, Drexler HG. Treatment of mycoplasma contamination in cell cultures with Plasmocin. J Biomed Biotechnol. 2012;2012:267678.

9. Cotter TW, Ramsey KH, Miranpuri GS, Poulsen CE, Byrne GI. Dissemination of Chlamydia trachomatis chronic genital tract infection in gamma interferon gene knockout mice. Infect Immun. 1997;65(6):2145-52.

10. O'Connell K, Nicks KM. A plasmid-cured Chlamydia muridarum strain displays altered plaque morphology and reduced infectivity in cell culture. Microbiology. 2006;152:1601-7.

11. Wooters MA, Kaufhold RM, Field JA, Indrawati L, Heinrichs JH, Smith JG. A real-time quantitative polymerase chain reaction assay for the detection of Chlamydia in the mouse genital tract model. Diagn Microbiol Infect Dis. 2009;63(2):140-7.

12. Hanna $L$, Thygeson $P$, Jawetz E. Elementary-body virus isolated from clinical trachoma in California. Science. 1959:130:1339-40.

13. Ramsey KH, Sigar IM, Schripsema JH, Denman CJ, Bowlin AK, Myers GA, Rank RG. Strain and virulence diversity in the mouse pathogen Chlamydia muridarum. Infect Immun. 2009;77:3284-93.

14. Grayston JT, Kuo C-C, Wang SP, Altman J. A new Chlamydia psittaci strain, TWAR, isolated in acute respiratory tract infections. N Engl J Med. 1986;315(11):161-8 